\title{
CONTRIBUIÇÕES DO PIBID E DO ESTÁGIO SUPERVISIONADO NA FORMAÇÃO IDENTITÁRIA DOS LICENCIANDOS DE LETRAS E PEDAGOGIA DA UEMG - CAMPUS DIVINÓPOLIS/MG
}

\author{
Elaine Kendall Santana SILVA \\ Universidade do Estado de Minas Gerais \\ Ana Paula Martins FONSECA \\ Universidade do estado de Minas Gerais \\ Geralda Pinto FERREIRA \\ Universidade do Estado de Minas Gerais \\ Regina Aparecida de MORAIS \\ Universidade do Estado de Minas Gerais \\ Rosana Rios CORGOZINHO \\ Universidade do Estado de Minas Gerais
}

\begin{abstract}
RESUMO: O presente artigo tem o objetivo de apresentar reflexões sobre a contribuição do PIBID e do Estágio Supervisionado no processo de construção identitária de licenciandos de Letras e de Pedagogia da UEMG. Para isso, buscou-se investigar, as estratégias de textualização usadas pelos licenciandos, focalizando o jogo interlocutivo, a inserção e o gerenciamento de vozes que se instauram na trama discursiva de questionários e relatórios, produzidos pelos licenciandos e, ainda, como se constroem as representações que esses alunos têm sobre a profissão "professor", analisadas a partir das respostas dadas aos questionários. Para entender como se dá a construção identitária de professores em formação, é preciso que se tenha em mente que tal construção revela um conjunto de representações, de idéias que os sujeitos da pesquisa têm dessa profissão. Pode-se afirmar que essas ideias, essa visão da profissão não existe desvinculada da linguagem. Por isso, a pesquisa embasou-se nos estudos de Bakhtin (1999), Koch (2003), Matencio (2004), Matencio e Silva (2003), dentre outros, que discutem sobre questões relacionadas ao funcionamento da língua(gem).
\end{abstract}

PALAVRAS-CHAVE: professor; construção identitária; ensino.

\begin{abstract}
This article has as a goal present reflexions about contributions on "PIBID" and from the supervisioned internship in the process of identity construction and graduates from "letras" and "pedagogia" UEMG.The purpose of this work was to investigate the textualization strategies used by the graduates, focusing on interlocutive play ,the insertion and management of voices that are established in the discursive web of questionnaires and reports produced by the graduates and still how is build the representation that this students have about the profession called teacher, analyzed by the answers that was obtained on the questionnaires. To understand how to give the identity construction of teachers in formation is necessary to have in mind that such a construction reveals a set of representations of ideas that the subjects of this research have of that profession.It can be affirmed that those ideas , this vision of the language don't exist unlinked with the language. Because of that the research based on study's from Bakhtin(1999), Koch (2003), Matencio (2004), Matencio e Silvia (2003) among others that discuss about questions related with the functioning of the language.
\end{abstract}

KEY-WORDS: teacher; identity construction; teaching 


\section{Introdução}

A relação teoria e prática na formação de professores em todos os níveis de ensino tem sido motivo de discussão e reflexão. Como alerta Paulo Freire $(1999$, p. 24) "a reflexão crítica sobre a prática se torna uma exigência da relação Teoria/Prática, sem a qual a teoria pode ir virando blablablá e a prática, ativismo". Há, portanto, que se ter o cuidado para que a teoria não seja apresentada de forma descontextualizada e vazia, como mera retórica, e que a prática, por sua vez, não caia em um ativismo estéril e sem significado para as práticas sociais de todos os envolvidos no processo - professores, alunos e toda a comunidade escolar. Essa é uma discussão presente também nos cursos de Pedagogia e Letras da UEMG, campus de Divinópolis/MG, que continuamente questionam a pertinência dos projetos que desenvolve, em relação à efetiva articulação entre teoria e prática, buscando possibilitar aos alunos uma reflexão crítica sobre a prática escolar. Para contribuir com essa reflexão é importante que o professor em formação posicione-se identitariamente frente a essas reflexões, pois, assim, poderá assumir melhor seu papel como profissional da área em que atua.

Com projetos pedagógicos comprometidos com a formação de professores reflexivos, capazes de compreender o contexto mais amplo em que se insere a instituição escolar, o curso de Letras e o de Pedagogia se pautam por uma proposta inter e transdisciplinar, que busca dar conta da complexa realidade sócio-político-educacional em que os alunos já atuam ou irão atuar. Os cursos objetivam, assim, formar profissionais que possam ter uma compreensão da realidade que lhes permita intervir criticamente nas práticas de sala de aula e no cotidiano escolar. Para educar crianças e jovens, em meio à grande diversidade sociocultural presente nas escolas, é necessário contar com professores altamente preparados e competentes.

Nesse sentido, os cursos se pautam pela práxis - reflexão-na-ação, educação pela pesquisa e formação humana. Há um empenho constante na busca de relação entre teoria e prática, considerando-se que a práxis pedagógica se constitui em um dos pilares dos cursos, que, como já dito, se pautam pela ação-reflexão-ação. Os Seminários Interdisciplinares, as Metodologias de Ensino, as propostas de Estágio Supervisionado, bem como as demais disciplinas, trazem em seu bojo modalidades de ações pedagógicas que visam a aproximação entre teoria e prática, propiciando aos alunos a percepção de que ambas fazem parte da mesma realidade e que se alimentam mutuamente. Pela reflexão sobre a ação e reflexão sobre a reflexão-na-ação, à qual os alunos são instigados continuamente, busca-se formar profissionais capazes de compreender a realidade em que atuam ou irão atuar e de intervir criticamente nas práticas de sala de aula e no cotidiano escolar.

Assim, na proposta dos citados cursos está presente o compromisso social e ético com a formação de professores críticos, autônomos e compromissados com a sociedade; professores que sejam capazes de preparar alunos para se tornarem cidadãos ativos e participantes em seu meio, o que está expresso na competência técnica e no compromisso político do profissional que se quer formar neste contexto, o presente projeto propiciou uma reflexão sobre a articulação entre a teoria ensinada no curso de Letras e no de Pedagogia do ISED e a prática vivenciada pelos alunos através do PIBID e do Estágio Supervisionado.

\section{Metodologia}


O objetivo geral desse projeto de pesquisa foi investigar, através da análise das estratégias de textualização, como se dá a construção identitária do professor em formação nos cursos de Letras e de Pedagogia da cidade de Divinópolis, através do PIBID e do Estágio Supervisionado, focalizando o jogo interlocutivo, a inserção e o gerenciamento de vozes que se instauram na trama discursiva de relatórios de estágio. Para isso, foi proposta aos alunos a produção de um relatório reflexivo - entendendo-se esse gênero textual como um texto no qual os alunos registram suas expectativas, descobertas e reflexões, realizadas no decorrer do PIBID e do Estágio Supervisionado. Foi, também, objetivo dessa pesquisa analisar as representações que esse aluno tinha/tem sobre a profissão "professor", através da análise de respostas dadas aos questionários e se, através das pistas linguísticas, é possível verificar diferença na construção identitária de bolsistas que vivenciam/vivenciaram o PIBID e de alunos que fazem somente o Estágio Supervisionado.

Os pesquisadores interessam-se pelo processo de referenciação textual, pelos mecanismos enunciativos e pela construção da identidade profissional, bem como pelas representações sociais sobre a profissão escolhida. A equipe trabalhou com dados de natureza documental e com dados coletados através de questionários. Considerando-se a materialidade dos dados e os princípios teórico-metodológicos adotados, a pesquisa que ora se propõe, foi, fundamentalmente, interpretativa e qualitativa. Portanto, o corpus para a análise consistiu em:

1) Questionários feitos com quarenta (40) alunos que estão em curso, um no início da pesquisa, respondido por vinte (20) alunos de cada curso e outro ao final, respondido pelos mesmos alunos. Estes questionários continham questões que possibilitam perceber sua concepção sobre o que é ser professor e sobre uma possível diferença entre a vivência no PIBID e no Estágio Supervisionado.

2) Quarenta (40) textos escritos, no gênero textual "relatório", produzidos pelos estudantes no decorrer do PIBID e do Estágio Supervisionado;

A pesquisa proposta volta-se para a questão do discurso e das reflexões de estudantes em curso, em que se buscou perceber a relação que têm construído entre a teoria e a prática docente e de que maneira o PIBID e o Estágio Supervisionado têm contribuído para tal construção. Vale ressaltar que parte-se, aqui, da concepção de que toda e qualquer atividade de ensino (conteúdo, metodologia, avaliação) realizada pelo sujeito - o professor - revela sua identidade profissional que, por sua vez, revela a compreensão e a interpretação desse sujeito acerca da realidade de uma maneira geral e, de modo específico, do fenômeno em si - o ensino/aprendizagem.

Além disso, pretendíamos entender como se dá a construção identitária desses professores em formação e foi preciso ter em mente que tal construção revela um conjunto de representações, de ideias que os sujeitos da pesquisas tinham/têm dessa profissão. Pode-se afirmar que essas ideias, essa visão da profissão não existe desvinculada da linguagem; por isso, a essa visão corresponde um determinado discurso que a materializa. Há que se ressaltar também que essa determinada visão de mundo, embora absorvida pela consciência individual, é socialmente produzida: a enunciação, ainda que realizada por um organismo individual, é, do ponto de vista do seu conteúdo, de sua significação, organizada fora do indivíduo pelas condições extra 
orgânicas do meio social. A partir dessa visão bakhtiniana do caráter coletivo (social) de produção das ideias, pode-se dizer que o conteúdo da consciência dos estudantes em formação inclui naturalmente uma concepção sobre o que é ser professor, que é apreendida por eles ao longo de sua formação, de sua inserção em um determinado grupo social.

Finalmente, pode-se dizer que, ao analisar o discurso desses alunos/professores, seja através da trama discursiva observada nas respostas dadas aos questionários, ou em seu relatório, a construção da identidade profissional dos alunos dos cursos de Letras e de Pedagogia da UEMG - unidade Divinópolis, ganha a visibilidade ainda não conquistada e possibilitar uma reflexão acerca de aspectos relevantes para a formação de professores da Educação Básica.

\section{Resultados e discussão}

Um dos pressupostos teóricos que embasam esta pesquisa diz respeito à noção de referenciação, pois ela exerce um papel bastante importante na tentativa de se compreender como ocorre o processo de construção de identidade profissional sob a luz das estratégias textuais- discursivas. Esse assunto tem sido tratado por diversos autores, tais como, Mondada e Dubois (2003), Marcuschi (2001) e Koch (2001). No decorrer de seus estudos sobre esse processo, esses autores discordam da concepção tradicional, segundo a qual a noção de referência está relacionada a um processo de correspondência entre um termo linguístico e um objeto situado no mundo extralinguístico, ou seja, segundo a qual um nome ou expressão usados para se referir a alguma coisa só terão valor de verdade se estiverem ligados a uma situação verdadeira do mundo real e exterior. De acordo com essa concepção à qual os autores se opõem, é necessário que haja uma relação clara, direta e objetiva entre a linguagem e o mundo. Dessa forma, há uma etiquetagem dos seres, sendo os referentes considerados objetos do mundo.

Ao invés de adotarem essa concepção de referência, os autores citados preferem utilizar o termo referenciação, e procuram ressaltar o caráter dinâmico e interativo desse processo. Segundo a perspectiva adotada por eles, o sentido das palavras e dos textos não é imanente, não se depreende de forma previamente estabelecida, mas, sim, de forma dinâmica, adaptável, no sentido de que existe a possibilidade de negociação entre os interlocutores.

É importante que a questão da referenciação seja tratada, pois esse é um fenômeno que está diretamente relacionado ao objeto de pesquisa deste trabalho. Afinal, pelo processo de referenciação, tem-se acesso à construção de objetos de discurso e através desse acesso podese compreender o que os sujeitos constroem como representações de determinado conceito.

Por essa razão, essa pesquisa está de acordo com Koch (2003, p.79), quando afirma que "a referenciação constitui uma atividade discursiva", e também com Mondada e Dubois (2003) que, além de defenderem esse pressuposto, parecem defender também a ideia de que não há relação entre as palavras e as coisas, mas apenas relações entre objetos de discurso. Assim, "a instabilidade das categorias está ligada as suas ocorrências, uma vez que elas estão situadas em práticas: práticas dependentes tanto de processos de enunciação como de atividades cognitivas não necessariamente verbalizadas" (MONDADA \& DUBOIS, 2003, p.29). É 
possível compreender, então, que as expressões linguísticas não são, por si sós, suficientes para a construção de sentido, porém, elas podem servir de "pistas" para que os interlocutores acionem seus diversos conhecimentos partilhados e atribuam sentidos a essas expressões. Sendo assim, numa concepção interacional da língua, a compreensão não é apenas uma simples decodificação, mas é, como diz Koch (2003), uma atividade interativa bastante complexa de produção de sentidos. É essa partilha de conhecimentos entre os participantes da ação comunicativa que lhes permite acionar os referentes e torná-los objetos de discurso.

Com isso, o enunciador, em função de fatores intra ou extradiscursivos, pode sempre decidir pela homologação ou não, por meio de suas escolhas lexicais, de uma transformação ou mudança de estado constatada ou predicada. Simetricamente, ele pode também alterar a categorização de um objeto independentemente de toda e qualquer transformação asseverada a respeito deste (APOTHÉLOZ \& REICHLER-BÉGUELIN apud KOCH, 2003: 80).

Essa transformação ou mudança de estado ocorre porque o sujeito irá categorizar um objeto de acordo com a atividade que está sendo desenvolvida e de seu contexto. Isso pode ser observado, no caso dos relatórios, através de alguns fenômenos, tais como os mecanismos enunciativos, pelos quais pode-se observar como o aluno realiza o gerenciamento de vozes; o uso de operadores discursivos, com os quais o aluno introduz considerações sobre sua prática no Estágio Supervisionado e os modalizadores, pelos quais os alunos vão introduzindo, produzindo e/ou qualificando os objetos de discurso no decorrer do texto e vão, assim, construindo os sentidos para o que foi estudado (teoria) e vivenciado (prática). Assim, ao produzirem os relatórios, os alunos estão em "interação" com os autores dos textos estudados para a realização do estágio e sua própria prática docente.

Para tratar dos mecanismos enunciativos, esta pesquisa embasou-se nos pressupostos de Bakhtin (1999) para quem um discurso é sempre perpassado por outros discursos que o precederam. Assim, para esse autor, toda enunciação, por mais original que seja, é constituída a partir de outros discursos, com os quais ela pode estabelecer vários tipos de relação: de concordância, de discordância, de assimilação, etc. Ao referir-se ao discurso do outro, ele afirma que "O discurso citado é o "discurso no discurso, a enunciação na enunciação", mas é ao mesmo tempo, um "discurso sobre o discurso", uma "enunciação sobre a enunciação". (1999, p. 144).

Portanto, o sujeito constrói seu discurso dialogando com as diversas vozes que já se manifestaram sobre o objeto discursivo que está sendo construído. Pode-se dizer, então, que toda enunciação é dialógica, pois contém em sua construção outras vozes, além daquela que se manifesta no momento da enunciação. Tal manifestação pode ocorrer de forma explícita e/ou implícita e é tratada por Authier-Revuz (apud CHARAUDEAU e MAINGUENEAU, 2004, p.261) como heterogeneidade mostrada e heterogeneidade constitutiva.

A heterogeneidade mostrada é aquela na qual a voz do outro se inscreve de maneira explícita no fio discursivo e inclui as seguintes formas de introdução da voz do outro: o discurso direto, o discurso indireto, o discurso direto livre, o discurso indireto livre, as aspas, o itálico, o discurso narrativizado. Já a heterogeneidade constitutiva é aquela na qual o discurso é dominado pelo interdiscurso. Assim, pode-se dizer que ele não é apenas um "espaço no qual 
viria introduzir-se, do exterior, o discurso outro; ele se constitui através de um debate com a alteridade, independentemente de qualquer traço visível de citação, alusão, etc.”. (CHARAUDEAU e MAINGUENEAU, 2004, p. 261).

O relatório reflexivo é uma atividade discursiva que pressupõe um diálogo com as produções teóricas que embasam o curso e as próprias reflexões do estudante, portanto, é comum haver um entrecruzamento de vozes na sua trama textual-discursiva que podem falar de perspectivas semelhantes ou não às do autor do texto-base. Isso ocorre, pois, de acordo com Bakhtin (op. cit), quando há o recurso ao discurso do outro, embora não ocorra um diálogo, propriamente dito, há uma manifestação dialógica, na qual o discurso encontra o discurso do outro, estabelecendo, assim, uma interação. Essa interação, isto é, esse entrecruzamento de vozes pode ocorrer, como já dito, de forma explícita ou implícita, podendo o aluno utilizar estratégias textual-discursivas tais como a citação, a evocação, o discurso direto e o discurso indireto. E podem, ainda, ser utilizados mecanismos tais como as modalizações, a ironia, a reformulação, a imitação, a paráfrase. A utilização desses mecanismos e as formas através das quais eles se manifestam permite compreender as relações estabelecidas entre as instâncias enunciativas - autor do texto-base/aluno - e podem, também, caracterizar a configuração textual e o funcionamento sócio comunicativo do relatório.

Além disso, a maneira como o aluno realiza o gerenciamento de vozes possibilita a pressuposição de suas representações sobre os aspectos teóricos e práticos da profissão docente. Pode-se dizer, assim, que uma investigação que tome os mecanismos enunciativos como objeto de análise, como é o caso desta pesquisa, é importante, pois eles indicam o posicionamento do aluno em sua enunciação, na relação estabelecida com o discurso dos autores dos textos trabalhados durante o estágio e seu próprio discurso, e entre o discurso de cada autor e o discurso daqueles com os quais cada um dialoga. Para compreender essa construção pela qual passa o aluno, é necessário verificar, nas atividades de escrita, as representações e as transformações sobre seu posicionamento identitário cujas contribuições advêm dos estudos de Moscovici (2003), em que o autor define Representações Sociais da seguinte maneira:

Um sistema de valores, ideias e práticas, com uma dupla função: primeiro, estabelecer uma ordem que possibilitará às pessoas orientar-se em seu mundo material e social e controlá-lo; e, em segundo lugar, possibilitar que a comunicação seja possível entre os membros de uma comunidade, fornecendo-lhes um código para nomear e classificar, sem ambiguidade, os vários aspectos de seu mundo e da sua história individual e social (MOSCOVICI, 2003, p. 21). Parece coerente dizer que, para Moscovici (2003), as Representações Sociais orientam os sujeitos quanto aos conhecimentos que são classificados e negociados de acordo com as práticas discursivas em que estão inseridos.

De acordo com esse autor, as representações sociais podem ser pensadas como "estruturas que conseguiram uma estabilidade, através duma estrutura anterior" de modo que a adesão a esse conceito remete-nos não apenas a uma conceituação, mas, principalmente, ao fenômeno das Representações Sociais, agora pensadas como um sistema de "crenças, dos conhecimentos e das opiniões que são produzidas e partilhadas pelos mesmos indivíduos de um mesmo grupo, a respeito de um dado objeto" (GUIMELLI apud CHARAUDEAU \& MAINGUENEAU, 2004, p.432). 
Considerando esse compartilhamento, parece coerente pensar que o posicionamento identitário dos sujeitos desta pesquisa embasa-se numa estrutura anterior que, em alguns casos, podem ser provenientes de práticas discursivas em que eles desempenhavam o papel de aluno da educação básica, podendo ser reafirmados ou desconstruídos, gerando novas representações no momento em que eles assumem o papel social de alunos graduandos (professores em formação) ou podem, ainda, ser construídos em situações em que esses sujeitos assumem a função de professor dos anos iniciais. Para que a noção de Representações Sociais seja melhor compreendida, torna-se importante tratar de dois mecanismos citados por Moscovici, chamados de ancoragem e objetivação. De acordo com este autor, para transformar ideias, seres ou palavras não familiarizadas em palavras usuais, próximas da realidade, é preciso colocar em funcionamento os mecanismos citados, que se baseiam na memória e em conclusões passadas. No mecanismo de ancoragem, as ideias que não são familiares são ancoradas, ou seja, são reduzidas a categorias e imagens comuns; são, então, colocadas em um contexto familiar. O outro mecanismo, chamado de objetivação, é definido da seguinte forma: "Objetivação une a ideia de não-familiaridade com a de realidade, [...] objetivar é descobrir a qualidade icônica de uma ideia, ou ser impreciso, é reproduzir um conceito em uma imagem" (op. cit., p.71).

Portanto, quando o aluno - sujeito da pesquisa - une as reflexões propiciadas no curso à suas próprias reflexões a partir do estágio, ele irá ancorar aquilo que era desconhecido em uma realidade conhecida, e irá, também, condensar os diferentes significados de sua prática docente em uma realidade familiar. Todo esse movimento poderá ser percebido através das modificações manifestas em seus textos e também através daquilo que se mantém, que direciona as práticas sociais que "emergem desse modo como processo que ao mesmo tempo desafia e produz, repete e supera, que é formado, mas que também forma a vida social de uma comunidade". (JOVCHELOVITCH, 2003, p.82).

Como defendido por Paulo Freire (1996) "a educação qualquer que seja ela é sempre uma teoria do conhecimento posta em prática". Portanto, a educação é uma teoria prática e por isso, os futuros educadores só têm um real entendimento da mesma ao conhecerem o ambiente escolar, que é oportunizado pelo Estágio Supervisionado e pelo PIBID. Sendo assim, com relação às conclusões possibilitadas pela aplicação da pesquisa, cabe esclarecer, de forma breve, algumas características do estudo realizado.

No caso desta pesquisa, que possui caráter empírico de natureza qualitativa, o que interessa aos pesquisadores não se limita somente ao que dizem os enunciadores-estudantes, mas também a maneira como dizem; e, buscando responder às questões propostas, foi realizada a análise documental dos relatórios de estágio e dos questionários. Tal escolha se justifica por esta metodologia apontar diretamente para a visão e o discurso dos estudantes pesquisados e para o registro de suas lembranças e experiências. Através dos procedimentos adotados pela equipe de pesquisa foi possível descortinar as ideologias presentes em seus discursos, seus sentimentos e visão da realidade, que constituem a trama do assunto investigado.

Foram aplicados, aos alunos que estão em curso, um questionário no início do ano e um no final, ambos com as mesmas questões, com o objetivo de perceber a representação identitária profissional que o aluno apresentava no início da pesquisa e suas possíveis (trans) formações 
ao final. Foram dadas, também, a esses alunos, as orientações para a escrita do relatório, também analisado pelos pesquisadores. Ambos foram acompanhados pelas professoras proponentes desse projeto

A escolha da aplicação de questionários escritos ocorre pelo fato de que a escrita inicia um processo de referenciação, que como defende Ducrot (apud MATENCIO, 2003), é uma "ação de estatuto ambíguo em que se tem o referente tanto como um elemento externo ao texto - por que é dito por outros tantos textos - quanto um elemento interno à materialidade textual pois nele se inscreve e nele se constrói” e, com isso, ao responder o questionário, o aluno não está apenas repetindo aquilo que aprendeu, mas construindo seu próprio conceito a partir daquilo que já sabe. Pensando nisso, foram analisados os questionários sob o foco de perceber o posicionamento dos discentes acerca da formação do professor e se há indícios de falas e teorias retextualizadas em seus discursos.

Em se tratando da questão "o que é ser professor?" muitas das respostas foram semelhantes. Tanto os estudantes de Letras quanto os de Pedagogia afirmaram que ser professor é aquele que repassa conhecimento de forma a contribuir para o desenvolvimento cognitivo e da cidadania dos seus alunos. Falas do tipo "Ser professor é estar apto a transferir conhecimento", "Ser professor é humanizar os alunos" e "é um pilar na formação das pessoas" foram observadas em vários questionários. Além disso, alguns estudantes argumentaram que deve haver uma relação dialógica entre o professor e aluno, como por exemplo, nas falas de alunos de ambos os cursos: "é estar sempre disposto a aprender com seus alunos" e "É ser mediador da aprendizagem, incentivando a curiosidade e a busca de novos saberes". Tal pensamento mostra que a crença de que o professor é detentor do conhecimento está sendo substituída pela ideia de que o conhecimento se desenvolve através da interação das partes.

Em contrapartida a esses argumentos, percebeu-se, também, que alguns estudantes não interpretaram corretamente a questão. Houve respostas tais como "é saber respeitar o próximo", "é ter amor ao cuidar e educar" e "é ser consciente (de) que seu ensino irá contribuir para a criança". Observou-se, então, que as respostas abordavam qualidades essenciais a qualquer ser humano e não especificamente ao professor. Isso parece demonstrar que pode haver problemas relacionados à interpretação feita pelos graduandos sobre o papel do professor. Essa interpretação pode estar relacionada às Representações Sociais que o graduando já tinha sobre a profissão antes de iniciar sua formação acadêmica, o que pode interferir na construção identitária deles.

Sobre a questão "Quais os aspectos que você considera relevantes na formação do professor de educação básica?" os estudantes de ambos os cursos apresentaram um pensamento semelhante: a necessidade da reformulação dos currículos, valorizando a atualização e o aperfeiçoamento metodológico. Além disso, viu-se que algumas respostas defendiam o uso de métodos lúdicos, respeitar e confiar na bagagem cultural dos alunos e unificar o "saber cientifico, estético, político e ético". Acerca do uso da ludicidade e de embasar-se no conhecimento prévio do graduando percebeu-se resquícios da teoria de sociointeracionista de Vygotsky, a qual preza a construção do conhecimento a partir da união dos conhecimentos de mundo e prévios dos indivíduos inseridos no processo educativo. Além disso, conclui-se que 
esse pensamento expressado no discurso dos discentes está ligado à futura identidade profissional desses indivíduos.

No tocante a questão "Qual a contribuição do PIBID para sua formação profissional?", respondida somente pelos alunos pertencentes ao citado programa, foram observadas respostas semelhantes, tanto nas respostas dos estudantes de Letras quanto nos questionários dos discentes de Pedagogia. Falas dos tipos "é através desse projeto que tenho um primeiro contato direto com a sala de aula", "me mostra a realidade de um professor" e "Com ele vivenciamos suas dificuldades. Aprendemos a criar e aplicar metodologias" mostram que, para os entrevistados, o PIBID possibilita uma melhor mediação entre o graduando e o ambiente escolar. Além disso, houve várias respostas relacionadas ao aprendizado de novas metodologias, o que salienta a importância desse programa para a formação dos graduandos.

Outro ponto observado nesses questionários foi o predomínio do pensamento de que o PIBID é o responsável pela efetivação e aplicação das teorias aprendidas nos cursos de graduação na prática docente. De acordo com Boas (2015) "Um professor vai se formando na relação teoria e prática, pois é a partir da ação e da reflexão que o professor se constrói enquanto indivíduo em pleno estado de mudança”.

Em relação à pergunta "Qual a contribuição do Estágio Supervisionado para a sua formação profissional", respondida, nesse caso, somente pelos estudantes que não participam do projeto PIBID, notou-se que o posicionamento dos graduandos de ambos os cursos foi semelhante, os argumentos foram, em sua maioria, construídos de forma similar. Foram notadas falas do tipo: "acho que ele é de extrema importância, pois dá a oportunidade aos alunos em formação de saberem o que de fato acontece em sala de aula", "o estágio proporciona aos alunos perceberem se a sua escolha profissional corresponde com a sua aptidão técnica" e "o estágio estabelece uma condição de ensino-aprendizagem, de exploração e pesquisa". Tais argumentos denotam que os licenciandos percebem a contribuição do estágio supervisionado para a sua formação profissional e que ele é o momento em que o estudante pode conhecer a realidade do ambiente do qual ele fará parte.

Em alguns questionários respondidos pelos graduandos do curso de Letras notou-se que algumas respostas possuíam argumentos idênticos, tais como: "é uma oportunidade de crescimento profissional e pessoal, além de ser um importante instrumento de integração entre escola, universidade e comunidade". Foi realizada uma averiguação dessas respostas junto aos professores orientadores de estágio e concluiu-se que esses alunos basearam-se nas falas deles para o seu discurso, e, portanto, elaboraram suas respostas a partir do processo de retextualização.

De acordo com Matencio (2003, p. 3) "ao processar um texto, o sujeito constrói, necessariamente, um quadro de referência em que ele instancia um contexto de situação em uma prática discursiva", ou seja, os estudantes adequaram um conhecimento a um contexto para consolidar seus argumentos a esse contexto. Contudo, em nenhuma das respostas foram feitas as devidas referências, para efetivar sua retextualiação. As partes retextualizadas foram incorporadas ao texto como parte do raciocínio dos discentes. 
A quinta e última pergunta do questionário "o que você acha importante ensinar ao seu aluno?" foi, também, respondida de modo semelhante pelos graduandos dos dois cursos. Foi comum ver frases como: "construir sua autonomia, pois é fundamental para o seu desenvolvimento social, intelectual e cognitivo."'; "Ensinar a ser crítico, autônomo e sempre estimular a curiosidade"; "O professor deve ensinar ao seu aluno o que é necessário para sua autonomia como aprendiz”. Foi abordado, principalmente, a formação da cidadania e do senso crítico dos alunos e que o uso do Currículo Básico Comum (CBC) é importante para a efetivação dessa formação como é visto na passagem: "Pautar sempre no CBC para que todos possam estar por dentro do ensino nacional".

Em se tratando dos relatórios feitos pelos graduandos de Letras e Pedagogia, observou-se que estes não possuíam as características básicas de referenciação e retextualização. De acordo com Matencio (2003, p. 3 - 4)

Retextualizar [...] envolve a produção de um novo texto a partir de um ou mais textos-base, o que significa que o sujeito trabalha sobre as estratégias linguísticas, textuais e discursivas identificadas no texto-base para, então, projetá-las tendo em vista uma nova situação de interação, portanto um novo enquadre e um novo quadro de referência.

Os relatórios foram construídos a partir das perspectivas dos estudantes e não foram acrescidos a eles fragmentos de textos-base. No entanto, viu-se que o posicionamento em relação ao estágio e ao PIBID mantém-se basicamente o mesmo e todos os relatórios:"a experiência adquirida em sala de aula contribuiu positivamente na compreensão das ações que devem ser realizadas para o melhor aprendizado"; "o estágio e o PIBID foram de suma importância para minha vida acadêmica e para o amadurecimento da ideia do 'ser professor' dentro de mim"; "ambas atividades, estágio e PIBID, contribuem para formação docente, nos fazendo ampliar nossa visão a respeito da educação e vencer nossas próprias barreiras e obstáculos enquanto professores".

Em contrapartida às respostas dadas aos questionários, notou-se que os relatórios foram produzidos com o intuito apenas de relatar os acontecimentos acerca do estágio e PIBID sem referência aos textos-base estudados, ao passo que os questionários foram respondidos de forma mais criteriosa, tendo, em alguns casos, respostas retextualizadas sobre o que foi repassado por seus orientadores. Mas, mesmo não tendo retomado explicitamente os textosbase, é possível perceber o posicionamento dos discentes e a formação identitária desses estudantes acerca da profissão escolhida.

\section{Considerações Finais}

Foi possível detectar que tanto os graduandos do curso de Letras quanto os do curso de Pedagogia possuem similaridades na forma de entender o "ser professor" e da importância do Estágio Supervisionado e do PIBID para sua formação, uma vez que ambas as ações possuem características comuns. Tanto o PIBID quanto o Estágio Supervisionado promovem um diálogo entre Universidade e Escola; Graduandos e Professores da rede pública; Graduandos e 
alunos de nível fundamental e médio. Foi fundamental, também, perceber a importância do estágio supervisionado e do PIBID na formação dos novos educadores, pois eles propiciam que o graduando conheça o dia-a-dia do professor, suas dificuldades e realizações, e para que compreendam também o ambiente da sala de aula em uma visão que não seja a do aluno da educação básica.

Essa ampliação da visão do futuro professor com relação ao ambiente escolar torna-se primordial, uma vez que foi neste ambiente que ele escolheu ingressar profissionalmente. Com isso, do ponto de vista da pesquisa e com base nas informações que já foram adquiridas, bem como no suporte teórico estudado, torna-se possível entender a importância de uma análise aprofundada do relato daqueles que já passaram por esta etapa de sua graduação, e dos que estão vivenciando-a. Isso contribuirá para que se perceba como suas ideologias acabam baseando-se nas teorias que estudam, inclusive, nas disciplinas de Estágio Supervisionado lecionadas na graduação e no referencial teórico visto no PIBID, que demonstram uma considerável influência em sua formação e na construção de suas identidades.

\section{Referências}

BAKHTIN, Mikhail Mikhailovitch. Marxismo e filosofia da linguagem: problemas fundamentais do método sociológico na ciência da linguagem. Tradução de Michel Lahud e Yara Frateschi Vieira. São Paulo: Hucitec, 1999.

BOAS, Gilmara. A importância das teorias na prática pedagógica. Disponível em: <portaldaeducação.com.br > Acesso em: 25 jul 2015.

FREIRE, Paulo. Pedagogia da autonomia: saberes necessários à prática docente. $33^{\mathrm{a}}$ ed. São Paulo: Paz e Terra, 1996.

JOVCHELOVITCH, Sandra. Vivendo a vida com os outros: intersubjetividade, espaço público e Representações Sociais. In: Guarescchi, Pedrinho A., JOVCHELOVTCH, Sandra (orgs.) Textos em representações sociais. Petrópolis, RJ: Vozes, 2003.

$\mathrm{KOCH}$, Ingedore Grunfeld Villaça. A referenciação como atividade cognitivo-discursiva e interacional.Caderno de estudos lingüísticos, Campinas, n.41, Jul. /Dez. 2001.

KOCH, Ingedore Grunfeld Villaça. Desvendando os segredos do texto. São Paulo: Cortez, 2003.

MAINGUENEAU, Dominique. Análise de textos de comunicação. Trad. de Cecília P. de Souza e Silva, Décio Rocha. São Paulo: Cortez, 2004.

MARCUSCHI, Luiz Antônio. Atividades de referenciação no processo de produção textual e o ensino de língua. Trabalho elaborado para o I Encontro Nacional do GELCO, Campo Grande, 2001 
MATENCIO, Maria de Lourdes Meirelles. Referenciação e retextualização de textos acadêmicos: um estudo do resumo e da resenha. Texto publicado nos ANAIS DO III CONGRESSO INTERNACIONAL DA ABRALIN - março de 2003.

MATENCIO, Maria de Lourdes Meirelles, SILVA, Jane Quintiliano. Retextualização: movimentos de aprendizagem. Texto publicado nos ANAIS DO II ENCONTRO INTERNACIONAL LINGUAGEM, CULTURA E COGNIÇÃO. Belo Horizonte: UFMG. 16 a 18 de julho de 2003 .

MONDADA, Lorenza, DUBOIS, Danièle. Construção dos objetos de discurso e categorização: uma abordagem dos processos de referenciação. In: CAVALCANTE, Mônica Magalhães, RODRIGUES, Bernadete Biasi, CIULLA, Alena (orgs.). Referenciação. São Paulo: Contexto, 2003.

MOSCOVICI, Serge. Representações sociais: investigações em psicologia social. In: Guarescchi, Pedrinho A., JOVCHELOVTCH, Sandra (orgs.) In: Textos em representações sociais. Petrópolis, RJ: Vozes, 2003. 